\title{
Educação integral com a infância e a juventude
}

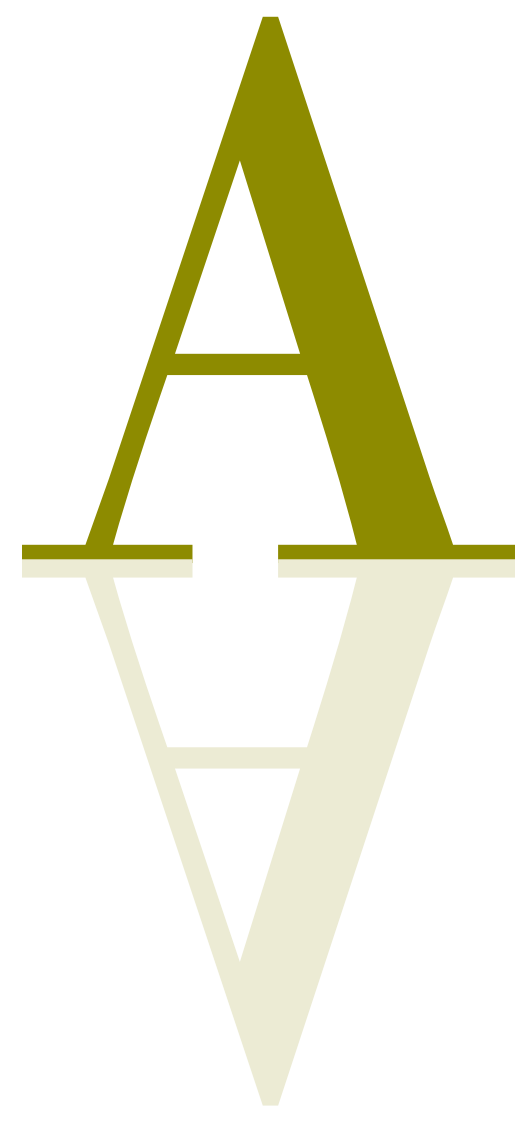

s idéias aqui apresentadas foram tecidas do lado de fora dos muros escolares, considerando os acontecimentos e os desafios que se encontram nessas fronteiras.

A aprendizagem se inicia com o nascimento e se estende ao longo de toda a vida, antecede e vai além do processo de escolarização, abarcando um amplo conjunto de instituições, modalidades, relações e práticas. A educação, a comunidade educativa e a política educativa são muito mais amplas que a educação escolar, a comunidade escolar e a política escolar.

Pretendemos circunscrever a abrangência do tema educação integral e, para tanto, iniciamos com um recorte histórico que configura a infância como categoria social e público prioritário da educação.

Esse histórico considera os aspectos de rupturas e contradições que fizeram a criança e o adolescente passarem "do anonimato para a condição de cidadão, com direitos e deveres aparentemente reconhecidos" (Del Priore, 1999, p. 8), ou seja, desde quando as crianças e os adolescentes eram considerados objetos de propriedade dos adultos, sem muita relevância, até os dias atuais, em que a Constituição Brasileira de 1988 prevê que as crianças sejam prioridade absoluta.

\section{Configurações da infância no mundo ocidental}

\section{0 processo de valorização da infância constituiu-se} entre os séculos XVI eXIX, segundo Philippe Ariès. Por um lado, as crianças, por sua ingenuidade, gentileza e graça, tornavam-se uma fonte de distração e de relaxamento para o adulto; por outro, transformavam-se em objeto

\footnotetext{
* Maria júlia Azevedo Gouveia é psicóloga, mestre em Educação e coordenadora da área da Educação e Comunidade do CENPEC. Colaboraram na reflexão e elaboração deste texto: Lúcia Helena Nilson, Ivana Boal, Stela Ferreira, Célia Pecci, Tatiana Bello, Wagner Santos.
} 
de estudo da psicologia e de preocupação moral, para que se fizesse, delas, pessoas racionais e cristãs, conciliando doçura e razão. A valorização da infância transitou da diversão aos cuidados de higiene e saúde com o corpo infantil; da educação, pela via das confrarias, à vida de rígida disciplina nos colégios.

O mesmo autor descreve a família abastada e suas mudanças da vida medieval à vida moderna, destacando a relação dos adultos com as crianças. No modo de vida antigo, a criança, assim que completava sete anos, ia morar em outra casa, com outros adultos, que também haviam transferido seus filhos para outra família. Essa nova moradia cumpria a função de educar as crianças pelo trabalho doméstico, quando então aprendiam os saberes do grupo familiar em que estavam inseridas. Esse tipo de aprendizagem ocorria à medida que realizavam os serviços domésticos e ajudavam na sobrevivência dessa família. 0 trabalho e a vida doméstica se confundiam, pois aconteciam no mesmo espaço. Nesse período, só freqüentavam a escola as crianças destinadas, pelos pais, ao clero. Elas eram, portanto, uma exceção.

Essa forma de relação das crianças com os adultos, na qual as crianças serviam uma família que não era a sua, implicava uma forte convivência entre eles e, dessa maneira, elas aprendiam a viver. A família era uma realidade moral e social, mais do que sentimental.

A família-casa (medieval) tinha, como traços marcantes, a circulação dos filhos e a escolha de apenas um como herdeiro, o primogênito, pois os outros eram encaminhados ao clero. Os clérigos, por sua vez, passaram a condenar a falta de consideração das famílias em relação à vocação de seus filhos e a valorizar que os pais nutrissem o sentimento e o tratamento de igualdade entre eles. Na realidade, esta é a prova do início de um sentimento que resultaria na igualdade entre os filhos no código civil. Assim, configura-se um valor novo: toda a realidade familiar baseia-se na afeição.

A família sentimental moderna (séc. XVII) separa-se do mundo e opõe, à sociedade, o grupo solitário dos pais e filhos. Toda a energia do grupo é consumida na promoção de cada criança, e não nutre qualquer ambição coletiva: as crianças, mais do que a família.

Não se pode esquecer que essa transformação da família medieval em família moderna se limitou, durante muito tempo, aos nobres, burgueses, artesãos e lavradores ricos. Até o final do século XIX, uma grande par-

\section{Entre 1550 e 1759, [...]}

o ensino, nos colégios $e$ seminários, tinha três fases: primária, média e superior. Na fase primária, destinada a alunos [...] de qualquer
classe social, excetuando os
escravos, aprendia-se a ler e
escrever. As outras duas fases
eram reservadas aos meninos
das famílias proprietárias
de terra.

te da população, a mais pobre e mais numerosa, vivia como as famílias medievais, com as crianças afastadas da casa dos pais.

Nesse mesmo processo em que a família se alterou, ou seja, em que a relação entre os adultos e as crianças se modificou, a escola também passou a ser considerada uma instituição relevante para cuidar e educar as crianças e adolescentes.

A escola e o colégio - que, na Idade Média, eram reservados a um pequeno número de clérigos e misturavam as diferentes idades dentro de um espírito de liberdade de costumes - tornaram-se, no início dos tempos modernos, um meio de isolar cada vez mais as crianças durante um período de formação tanto moral quanto intelectual, de adestrá-las graças a uma disciplina mais autoritária, e, desse modo, afastá-las da sociedade dos adultos. 0 colégio começou a separar os alunos em diversas séries escolares, impedindo assim o convívio entre as diferentes idades, preocupação que se tornou efetiva apenas no século XIX, pois, para a escola medieval, quando ingressava na escola, a criança entrava automaticamente no mundo dos adultos.

Essa mistura de idades continuava fora da escola. A escola não cerceava o aluno. 0 mestre único - às vezes assistido por um auxiliar e com uma única sala à sua disposição - não estava organizado para controlar a vida quotidiana de seus alunos. Estes, ao terminarem a lição, escapavam à sua autoridade.

Vimos desencadear-se uma transição do modelo escolar medieval - espaço cujo chão era forrado com paIha onde todos se sentavam - ao padrão moderno de colégio - espaço complexo, ditado pelas transformações pedagógicas e fundamentalmente pelo controle, constante e rigoroso, do corpo discente. 
Dois valores fundantes do trabalho educativo são expressos pela pedagogia: de um lado, as noções de inocência ou fraqueza da infância e, de outro, o da responsabilidade moral dos mestres. Em decorrência desses valores, o trabalho educativo apresenta três características principais: a vigilância constante e hierárquica, a delação como princípio de governo e prática institucional e a aplicação ampla de castigos corporais.

No trabalho educativo voltado para a infância, é introduzida a noção de disciplina que se apóia no tripé vigilância-delação-punição. Esta parece ser a principal diferença entre as duas modalidades históricas, a medieval e a moderna, de se conceber e efetivar o trabalho educacional. E, como se pode notar, enraíza-se, nessa transformação, boa parte das convicções pedagógicas que ainda hoje são testemunhadas nas salas de aula.

\section{Configurações da infância no Brasil}

\section{No Brasil, a infância ganhou maior visibilidade e inte-} resse no final do século XIX, quando a criança passou a ser considerada um ser em desenvolvimento. Esse novo olhar - que avalia a criança como um ser frágil, que demanda cuidados e proteção no decorrer de seu crescimento - constituiu uma estratégia para formar um adulto moldado às exigências de um Estado dito moderno.

Esse Estado precisava de uma população civil que incorporasse os ideais de pátria, de nação moderna (Costa, 1979), e, assim, começou a adotar a família e a escola como instituições de cuidado com a infância. Nesse contexto, o Estado, para alterar os valores e o modo de vida da sociedade, articulou-se aos médicos higienistas e a outros cientistas para produzir a mudança que julgava necessária.

A partir de então, a medicina social, como enfatiza Jurandir Freire Costa (1979, p. 33), dirigir-se-á à família, procurando modificar as condutas físicas, intelectuais, morais, sexuais e sociais de seus membros, a fim de propiciar a sua adaptação ao sistema econômico e político. Essa perspectiva tem uma característica generalizante, ou seja, dirigia-se a uma classe social específica, pois sua meta era o controle demográfico e político da população. Exemplo disso são as campanhas de vacinação para reduzir a mortalidade infantil, nas quais o Estado, aliado aos higienistas, mobiliza as famílias para que vacinem seus membros. 0 objetivo do governo passa a ser “melhorar a sorte da população, aumentar sua riqueza, sua duração de vida, sua saúde etc.” (idem, 289).
Nesse mesmo registro, a convivência familiar foi um dos aspectos da vida social para o qual os higienistas desenvolveram teorias e técnicas que revelavam a importância dos cuidados e da educação das crianças. Foram criadas normas que definiam a maneira adequada de a família educar e proteger a criança, desde o cuidado com a alimentação até a educação sexual. A ordem médica produzirá uma norma familiar, capaz de formar cidadãos individualizados, domesticados e colocados à disposição da cidade, do Estado e da pátria.

Esse novo olhar voltado para a criança (futuro cidadão) fazia dela o centro do contexto familiar e, em conseqüência, exigia um rearranjo das rotinas dos adultos. A vida na família ganha um novo caráter. Esta é uma face da mudança da visão de infância, que permitia que o cidadão estivesse a serviço dos interesses do Estado, e não das relações e da autoridade familiar. No entanto, isso ainda não era suficiente, e a educação das crianças passou a ser delegada a outros. A construção social da categoria infância só pôde ser consolidada pelas práticas de uma instituição: a escola. Nesta ação transformadora, os componentes de antigos dispositivos de controle, como a militarização e a pedagogia jesuítica, serão reaproveitados e orientados para outros fins.

A escola torna-se portadora da tarefa de formação dos homens para a sociedade, sendo responsável pelos aperfeiçoamentos físico, moral e intelectual das crianças. Para tanto, criaram-se múltiplas técnicas disciplinares que pretendiam institucionalizar uma instrução adequada aos alunos, valorizando o culto ao bom hábito por meio da domesticação do corpo e do espírito do indivíduo. Na família e na escola, instruir significava moralizar, disciplinar, fazer com que filhos e alunos pudessem amar e servir à "humanidade”, e, assim, educá-los, ou melhor, transformá-los em adultos a serviço da nação.

Aqui é necessário pontuar como a educação escolar acontecia em nosso país. Como relata Tobias (1986), entre 1550 e 1759, a educação escolar limitava-se à que era ministrada em alguns pontos do país pela Ordem dos Jesuítas: uma educação cristã, associada à catequese. 0 ensino, nos colégios e seminários, tinha três fases: primária, média e superior. Na fase primária, destinada a alunos - meninos brancos e índios - de qualquer classe social, excetuando os escravos, aprendia-se a ler e escrever. As outras duas fases eram reservadas aos meninos das famílias proprietárias de terra. 


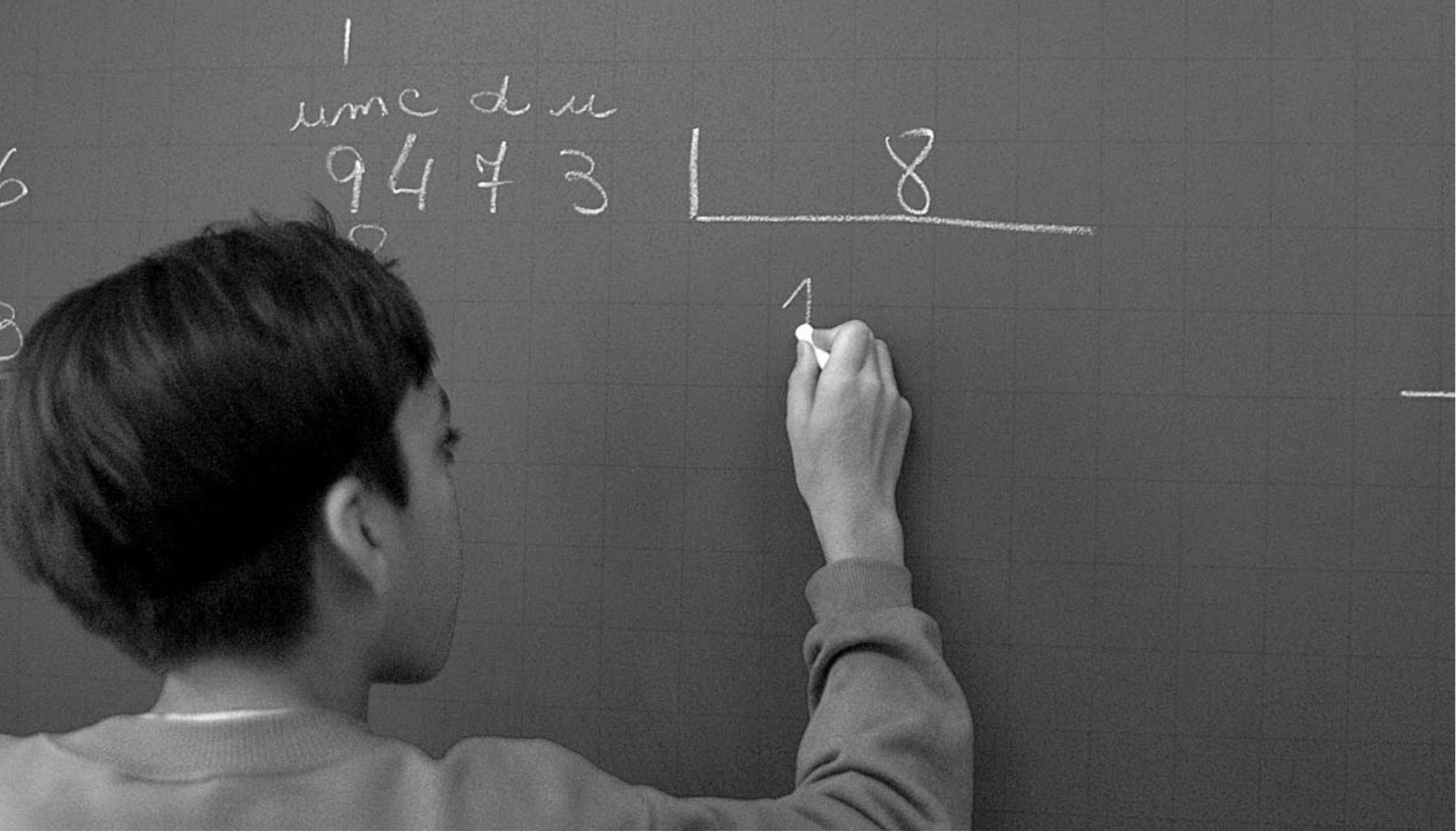

Dessa maneira, por meio da ordem jesuítica, a Igreja Católica, segundo Freitag (1980, p. 47), preparava os futuros bacharéis em Belas-Artes, Direito e Medicina, tanto no Brasil quanto em Portugal. Ela fornecia os quadros dirigentes da administração colonial, formava os teólogos e educadores - tinha hegemonia na sociedade civil.

Em 1759, os jesuítas foram expulsos do país; porém, as tarefas de educação permaneceram a cargo da Igreja. Apenas a partir da vinda da família real, em 1808, é que outras escolas (técnicas, academias) foram criadas. Depois da independência do país, foram criadas também escolas militares em diversos pontos do território nacional. Porém, apenas no fim do Império e início do período republicano é que aparecem os primeiros traços de uma política educacional estatal.

O Estado brasileiro inicia seu período republicano e urbano sob a égide do Estado Moderno. Assim, no processo de consolidação dessa nova forma de governo que não se dá mais pela hereditariedade - fez-se necessário, como mencionado, que ele se associasse às diversas disciplinas do conhecimento para validar suas práticas subjetivas (discurso político-jurídico) e objetivas (serviços públicos).

Encontramos uma narrativa na literatura que mostra um recorte dessa política educacional operando. Graci- liano Ramos (2002, p. 107-8), em seu livro Infância, narra o episódio de um garoto chegando à escola no início do século XX, numa sala de aula em que o autor (ainda menino) estava presente:

Vi chegar um rapazinho seguro por dois homens. Resistia, debatia-se, mordia, agarrava-se à porta e urrava, feroz. Entrou aos arrancos, e se conseguia soltar-se, tentava ganhar a calçada. Foi difícil subjugar o bicho brabo, sentá-lo, imobilizá-lo. 0 garoto caiu num choro largo. Examinei-o com espanto, desprezo e inveja. Não me seria possível espernear, berrar daquele jeito, exibir força, escoicear, utilizar os dentes, cuspir nas pessoas, espumante e selvagem. Tinham-me domado. Na civilização e na fraqueza, ia para onde me impeliam, muito dócil, muito leve (...).

Esse relato explicita a dureza da escolarização, exigente disciplinamento, para cujo entendimento Foucault (1987, p. 199) fornece referências. Com base na hipótese da "sociedade disciplinar", o autor traz contribuições fundamentais para a compreensão do disciplinamento difuso, indagando se "devemos ainda nos admirar que a prisão se pareça com as fábricas, com as escolas, com os quartéis, com os hospitais, e todos se pareçam com as prisões?”. Para ele, as instituições disciplinares teriam se constituído por meio de procedimentos de controle bastante minuciosos, dentre os 
quais destaco os que estão voltados à racionalização do espaço, do tempo e dos corpos dos indivíduos sob sua tutela.

Retomando o processo de constituição da infância no Brasil, vimos que as funções de educação e socialização do universo infantil são exercidas pela família e pela escola. Mantém-se, dessa forma, o objetivo do Estado de formar o cidadão como homem e o homem como cidadão (Cambi, 1999).

No entanto, o acesso à escola, como prática de cuidado e educação das crianças, não estaria disponível para todos. Vale destacar que a escola não se tornou uma possibilidade viável devido à inexistência de vagas para uma grande parte da população infantil pobre e, ao mesmo tempo, pela exclusão de muitas crianças, por não aprenderem ou não se adaptarem à rígida disciplina.

Para as populações pobres - e considerando que seus filhos não tinham acesso aos cuidados e à educação que a escola oferecia - restam o trabalho e as ruas como alternativa para "sua transformação em cidadãos úteis e produtivos" (Del Priore, 1999, p. 10). Ou seja, ou assumiam as responsabilidades do mundo adulto ou ficavam à mercê das "forças heterogêneas" do mundo, no dizer de Arendt (1997).

A diferença sociocultural que se estabelece no interior do universo da categoria infância, entre os que permanecem vinculados à escola e os que não têm acesso ou são expulsos dela, é tal que o conceito genérico de infância não poderá abarcá-los. Para García Mendez, "os excluídos se converterão em menores” (1998, p. 86).

Nesse contexto, a categoria infância já havia sido segmentada: de um lado, as crianças que podiam ser filhos e alunos e, de outro, aqueles a quem restava ser abandonado ou “menor". Para esses últimos, foi necessária a criação de uma instância de controle sociopenal, em 1927 - o tribunal de menores. Assim, um segmento da infância torna-se figura do Direito, e o universo da lei transforma-se em um dos mais importantes instrumentos de modificação da realidade.

Essa segmentação ainda tem marcas objetivas e subjetivas até os dias de hoje, embora, nas últimas duas décadas do século XX, muitas alterações tenham sido realizadas, como: a determinação legal de universalização do acesso à escolarização e o deslocamento realizado em função dessas crianças e adolescentes, que passaram da condição de objeto de tutela para a de sujeito de direitos.

\section{Caminhos da legislação}

\section{Para nós, a criança é um tripé: é sujeito de direito, su-} jeito de conhecimento e sujeito de desejo. Não nos colocamos à frente das crianças, fazemos um movimento de rotação para ficarmos ao lado delas, porque elas são o sujeito destas três origens fundamentais da vida (Cesare La Rocca).

Atualmente, a educação é a área de investimento mais visada em todo o mundo para produzir desenvolvimento. Países fazem revoluções econômicas e se deslocam no ranking de desenvolvimento por seu investimento em educação. Outra questão pertinente diz respeito ao enfrentamento das desigualdades que caracterizam a vida contemporânea no país e no mundo. Esta desigualdade convoca a todos para a formulação de ações que tenham a eqüidade como foco e, assim, permitam produzir igualdade de resultados.

Desde 1990, na Conferência Mundial sobre Educação para todos, realizada em Jomtien, Tailândia, vem sendo ampliado o consenso de que educação para todos se faz com todos pela educação. Essa posição, também adotada pelo Estatuto da Criança e do Adolescente - ECA, incluiu, no cenário educacional, outros atores, como as organizações não-governamentais, os movimentos sociais, os grupos culturais, a iniciativa privada, a mídia etc.

O ECA define as crianças e adolescentes como sujeitos de direitos demandantes de proteção integral que, para se realizar, exige articulação das políticas sociais e indica a assistência social como operadora da proteção social para a infância e juventude em situação de vulnerabilidade.

\section{Entendemos vulnerabilidade como uma situação de risco pessoal ou social. Não saber ler e inter- pretar textos após cinco anos de escolarização ca- racteriza uma situação de vulnerabilidade?}

A Lei Orgânica de Assistência Social (LOAS, 1993) define a proteção social como política pública de Estado e direito do cidadão, um importante avanço no sistema de proteção social brasileira. Desde a aprovação da LOAS, esta política pública vem sendo debatida e está instituindo uma construção política a partir de princípios explicitados na Política Nacional de Assistência Social (PNAS, 2004), dos quais podemos destacar: 
- Uma visão social capaz de entender que a população tem necessidades e também possibilidades ou capacidades que devem e podem ser desenvolvidas. Assim, uma análise de situação não pode considerar apenas as ausências (o que falta), deve contemplar também as presenças (o que existe), até mesmo como desejos de superar a situação atual.

- Uma visão social capaz de identificar as forças, e não as fragilidades, que as diversas situações de vida apresentam.

Além disso, a Assistência Social - como política pública que compõe o tripé da Seguridade Social e considerando as características da população atendida por ela -, deve fundamentalmente inserir-se na articulação intersetorial com outras políticas sociais, particularmente, as políticas de Saúde, Educação, Cultura, Esporte, Emprego, Habitação, entre outras, para que as ações não sejam fragmentadas e se mantenha o acesso e a qualidade dos serviços para todas as famílias e indivíduos.

Em 1996, a Lei de Diretrizes e Bases da Educação Nacional (LDB) prescreveu o aumento progressivo da jornada escolar para o regime de tempo integral, a critério dos sistemas de ensino (art.34 e 87), e ao mesmo tempo indica o regime de escolas em tempo integral. Também, reconhece a existência e valoriza as experiências extra-escolares (LDB, art. 3, item 10).

O Plano Nacional de Educação define, como diretriz e meta, que a ampliação da jornada deve possibilitar a "orientação no cumprimento dos deveres escolares, práticas de esporte, desenvolvimento de atividades artísticas e alimentação adequada, no mínimo em duas refeições” (PNE, 2000). Além disso, indica a escola de tempo integral "preferencialmente para as crianças das famílias de menor renda com as atividades descritas acima nos moldes do Programa de Renda Mínima Associado a Ações Socioeducativas" (PNE, 2000).

A lei permite que cada rede de ensino encontre o seu modo de atuar nesse tempo integral e aponta, como referência, o que se realiza no registro da proteção social (programa Renda Mínima). Portanto, uma interpretação possível é a realização do tempo integral utilizando outros espaços, além do escolar, para desenvolver esse trabalho.

Destacamos um traço que atravessa todas as referências legais, em maior ou menor intensidade: a perspectiva de articulação das políticas, pois a educação contemporânea precisa se concretizar por meio do entrelaçamento de ações educativas efetivas.
Nessa trilha, a educação integral se apresenta como uma oportunidade de agregar qualidade à escolarização e ao enfrentamento da iniqüidade educacional.

\section{A educação e seus desafios}

\section{Como vimos, a escola se manteve destinada a poucos} por muito tempo. Passetti (2000) mostra que, no início do século XX, no estado de São Paulo - pela Lei n. 1.070, de 16 de agosto de 1907 - o governo ficava autorizado a destinar $10 \%$ das vagas do ginásio para os alunos do primário que mais se distinguissem durante o ano e fossem comprovadamente pobres.

A escola que experimentamos no Brasil, até a década de 1970, era destinada a formar intelectuais, letrados, eruditos, homens de saber ou de arte, ou seja, atendia a poucos, a um pequeno grupo da elite.

Anísio Teixeira chama a atenção para o fato de que a escola não visava formar o cidadão, não visava formar o caráter, não visava formar o trabalhador, e, sim, formar o intelectual, o profissional das grandes profissões sacerdotais e liberais, o magistério superior e, assim, manter a cultura intelectual distinta da cultura do povo e independente da cultura econômica e de produção.

A escola para todos passa a ter dois objetivos: a formação geral e comum de todos os cidadãos e a formação dos quadros de trabalhadores especializados e de especialistas de todas as espécies, exigidos pela sociedade moderna.

A escola, como instituição forjada para educar intelectualmente crianças, adolescentes e jovens - e, mais ainda, o sistema escolar como política pública - vem enfrentando uma sucessão de crises, nos mais diversos âmbitos. Destacamos quatro aspectos da ação pedagógica que expressam pontos críticos:

- Os espaços escolares mantêm a mesma arquitetura e ocupação do início do século XX.

- A duração da hora-aula escolar é de 45 ou 50 minutos, portanto, todo e qualquer grupo e conjunto de conhecimento devem adaptar-se a esse tempo ou a um múltiplo dele.

- Os objetos de conhecimento são definidos a priori em disciplinas e colocados à disposição dos alunos gradativamente, segundo a lógica do próprio objeto.

- Os sujeitos ocupam lugares bem definidos: o professor deve saber e deve ensinar, o aluno não sabe e deve aprender, ou o professor, por saber, deve me- 
diar a relação do aluno - não-sabedor - com os objetos de conhecimento.

\section{No muro branco do populoso bairro caraquenho de Antímano, no oeste da capital venezuelana, lê-se um significativo grafite: “Agora, nós pobres também vamos à escola, para que não nos rou- bem o futuro".}

Desde a década de 1930, críticos, como Freinet, apontam que a escola é burocratizada, distante da família, teórica e dogmática, além de promover a passividade do aluno, o intelectualismo excessivo e o caráter desumano, porque, nas condições em que se encontram, os alunos não conseguem desenvolver habilidades de análise crítica, de julgamento pessoal, de expressão livre de seus próprios pensamentos e opiniões, de apresentação de propostas novas, de exercício de cooperação, de criatividade, de responsabilidade e de afetividade.
Com o esforço das últimas duas décadas de democratização da escolarização, chegamos a 98\% das crianças e adolescentes incluídas no ensino fundamental, ou meIhor, conseguimos garantir o acesso à matrícula escolar. Ao mesmo tempo, as avaliações indicam que parcela significativa dos estudantes não compreende textos, comprometendo, portanto, o restante do aprendizado.

Parece que o acesso e a presença não têm produzido aprendizagem. Vale aqui lembrar o que ensina Paulo Freire (2001) sobre o diálogo para a transformação: “A relação dialógica implica num falar com, e não num falar por ou num falar para, pois não se trata da conquista de uma pessoa por outra; senão que é uma conquista do mundo pelos sujeitos dialógicos".

\section{Novas práticas educativas}

Será que estamos falando por e para as nossas crianças e adolescentes? Estamos configurando um campo de

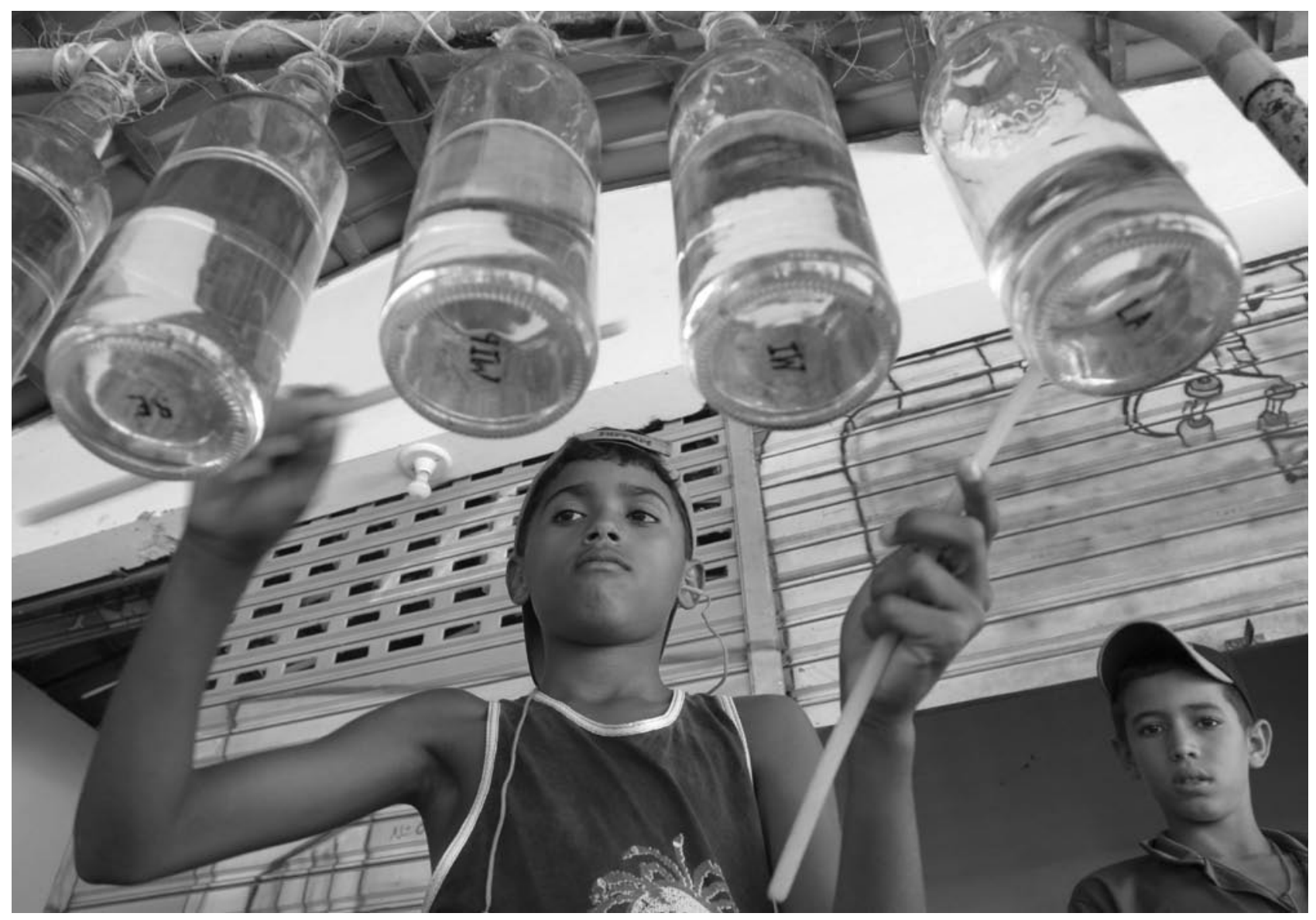


diálogo que permita que o aprendizado se processe?

Espaços paralelos à escola vêm circunscrevendo novas práticas educativas. Grupos comunitários, culturais, artísticos e de movimentos sociais desenvolvem atividades com crianças e adolescentes, objetivando ensinarlhes a tradição da cultura local, aproximá-las das produções artísticas, conscientizá-las de seus direitos, proporcionar-lhes práticas esportivas, valorizar as brincadeiras, promover eventos artísticos, acompanhar suas tarefas escolares, propiciar sua circulação pela cidade, experimentar a ocupação dos espaços públicos, acessar tecnologias, participar da vida pública, intervir na localidade onde vivem etc.

Denominamos, a este conjunto de iniciativas, de ações socioeducativas. Socioeducativas porque podem tomar a ética, a estética e a política como fonte de orientação para seus projetos de criação de situações de aprendizagem. Assim, a convivência, os sentimentos e os interesses humanos, portanto coletivos, são o cenário e o roteiro dessa diversidade de práticas desenvolvidas em diferentes localidades do país.

As ações socioeducativas, em seu desafio de educar na e para a convivência democrática, têm como perspectiva que:

- os sujeitos aprendentes e ensinantes ocupem lugares dinâmicos: o educador é o adulto que tem habilidades e competências, e as coloca à disposição da invenção de situações de aprendizagem que levam em consideração quem são os aprendizes interessados e possuidores de interesses diversos, com os quais vai empreender a aventura do conhecimento.

- os espaços são os lugares disponíveis e potencializadores da aprendizagem, lugares onde se encontram os objetos de conhecimento, a cidade, os caminhos etc. Locais que são ocupados pelos sujeitos, produzindo uma ambiência educativa.

- os tempos são definidos a partir dos sujeitos e objetos de conhecimento envolvidos na aprendizagem.

- os objetos de conhecimento estão no mundo, definem-se numa equação que coloca em relação as potências e as competências dos diversos sujeitos envolvidos. A apropriação ou reconstrução desses objetos pelos envolvidos se dá por meio de projetos que lançam, no futuro, um produto que realiza e comunica o aprendizado de todos, pois "aprender é conhecer e intervir no seu meio” (Cidade Escola Aprendiz, 2006).

\section{Para trabalhar com a perspectiva da educação integral, a ação pedagógica considera: todas as dimensões humanas; que todos os envolvidos são sujeitos da aprendizagem (adultos e criancas); os campos ético, estético e político como cenário e roteiro da aprendizagem.}

Estas ações - em sua capilaridade, respeito e valorização das diferenças - vêm realizando, embora desarticuladamente, os propósitos de diferentes políticas públicas. Conjugam, em sua ação empírica, a intenção de educação, de cultura e de proteção social. Tornam-se expressão da ação multisetorial.

As ações socioeducativas vêm sendo realizadas em todo o país por organizações não-governamentais e por governos municipais, com aporte financeiro federal ou estadual. Exemplos dessa prática são: a Jornada Ampliada ligada ao Programa de Erradicação do Trabalho Infantil - PETI- e o Programa Agente Jovem, o Programa Segundo Tempo do Ministério dos Esportes e atividades dos Pontos de Cultura do Ministério da Cultura. Em todos esses exemplos, há o fortalecimento da sociabilidade, da convivência, do repertório cultural e informacional, da prática esportiva, do acesso e uso da tecnologia, da participação na vida pública e cívica das comunidades em que vivem etc.

\section{Enfrentando a iniquiidade}

\section{Nos últimos anos, a sociedade brasileira começou a en-}

xergar a educação integral como um caminho para garantir uma educação pública de qualidade, capaz de contribuir para o desenvolvimento individual de cada criança, das comunidades e da sociedade como um todo.

Para garantir as aprendizagens necessárias à vida, ao trabalho, à participação e à cidadania plena, é necessário uma combinação de diferentes tempos e espaços, sempre definidos pelos objetos de conhecimento, os sujeitos e o contexto em que vivem.

Quando se fala de educação integral, alguns aspectos e princípios precisam ser considerados: 
- Dimensões humanas: a Educação Integral pretende captar a complexidade de uma pessoa em sua totalidade, com uma proposta de desenvolvimento que, ao mesmo tempo, é cognitivo, emotivo, espiritual e físico.

- Ciclo de vida: não se trata mais de pensar que apenas a idade escolar é a única em que podemos aprender. 0 aprendizado se dá ao longo da vida: crianças e adultos aprendem todo o tempo.

- Satisfações humanas: a qualidade de vida das pessoas é o centro da educação integral e, para isso, é preciso considerar as satisfações humanas: criação, proteção, afeto, compreensão, identidade, lazer-ócio, liberdade e participação.

- Garantia dos direitos de educação: é necessário que a proposta educacional seja do conhecimento de todos e avaliada por todos (aceitabilidade), que todos possam se incluir num processo de aprendizagem (acessibilidade), que todas as diferenças sejam consideradas e influenciem a proposta (adaptabilidade) e que estejam instaladas as capacidades necessárias para execução da proposta (exeqüibilidade).

- Integração das políticas: a educação integral exige uma visão transetorial, em que as políticas educativa, econômica, social e cultural sejam formuladas e operadas de forma a garantir qualidade de vida.

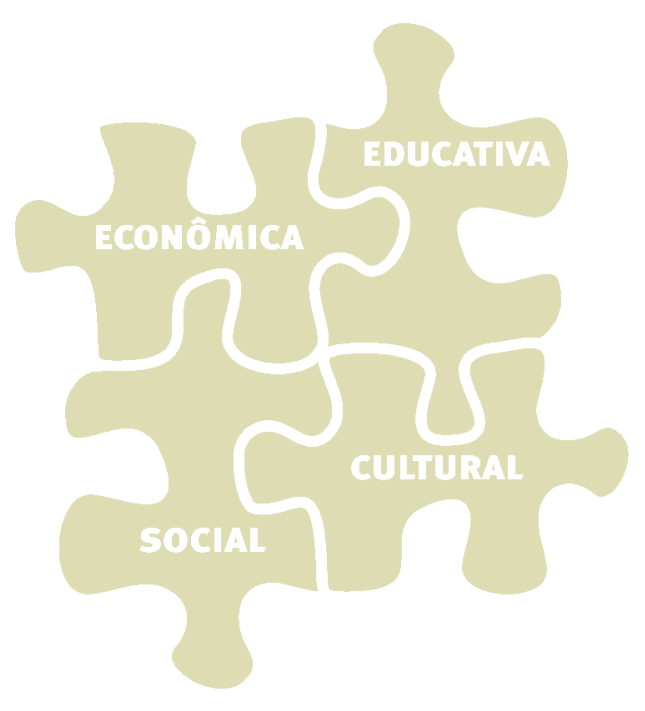

Para trabalhar com a perspectiva da educação integral, a ação pedagógica considera: todas as dimensões humanas; que todos os envolvidos são sujeitos da aprendizagem (adultos e crianças); os campos ético, estético e político como cenário e roteiro da aprendizagem.

Parece importante adotarmos uma visão "integral e sistêmica do educativo, colocando no centro a aprendizagem e a cultura em sentido amplo", como aponta a educadora Rosa Maria Torres.

Assim, a educação integral é realizada por meio de uma equação político-pedagógica que, sustentada por esses princípios, articula sujeitos da aprendizagem, objetos de conhecimento, tempos e espaços.

\section{Bibliografia}

AQUINO, J. G. Do cotidiano escolar: ensaios sobre a ética e seus avessos. São Paulo: Summus, 2000.

ARENDT, H. Entre o passado e o futuro. 5. ed. São Paulo: Perspectiva, 2002. 1997.

ARIÈS, P. História social da criança e da família. 2. ed. Rio de Janeiro: LTC, 1981. BRASLAVSKY, C. Dez fatores para uma educação de qualidade para todos no século XXI. São Paulo: Editora Moderna, 2004.

CAMBI, F. História da pedagogia. São Paulo: Unesp, 1999.

CARVALHO, M. C. B. A família contemporânea em debate. 2. ed. São Paulo: EDUC; Cortez, 1997.

CIDADE ESCOLA APRENDIZ. Educação Comunitária: trilhas educativas. São Paulo: Associação Cidade Escola Aprendiz, 2006.

CURY, M.; SILVA, A. F. A. e COSTA, A. C. G. Estatuto da criança e do

adolescente comentado: comentários jurídicos e sociais. São Paulo: Malheiros, 1992.

FOUCAULT. Vigiar e punir. 23. ed. Petrópolis: Vozes, 1987.

. A verdade e as formas jurídicas. Rio de Janeiro: Nau; PUC-RJ, 1999.

FREIRE, P. Pedagogia da autonomia. 29. ed. São Paulo: Paz e Terra, 2004.

FREITAG, B. Escola, estado e sociedade. 4. ed. São Paulo: Moraes, 1980.

GARCÍA MENDEZ, E. Infância e cidadania na América Latina. São Paulo: Hucitec; Instituto Ayrton Senna, 1998.

GUATARI, F. As três ecologias. São Paulo: Editora 34, 1978.

GOUVEIA, M. J. A. Contextos expulsivos. In: GREGORI, M. F. (Coord.). Desenhos familiares: pesquisa sobre família de crianças e adolescentes em situação de rua. São Paulo: Alegro, 2000, p. 111-6.

GOUVEIA, M. J. A. Imagens de "meninos de rua": da enunciação ao evanescimento, 2003. Dissertação (Mestrado). São Paulo. Faculdade de Educação FE/USP.

LA ROCCA, C. F. É tempo de recordar. In: BIANCHI, A. (Org.). Plantando Axé: uma proposta pedagógica. São Paulo: Cortez, 2000, p. 11-4.

MARCÍlIO, M. L. História social da criança abandonada. São Paulo: Hucitec, 1998.

PASSETI, E. (Coord.). Violentados: crianças, adolescentes e justiça. São Paulo: Imaginário, 1995.

ROCHA, M. C. A experiência de educar na rua: des-cobrindo possibilidades de ser-no-mundo, 200o. Dissertação (Mestrado). USP. São Paulo. (Mimeo).

TOBIAS, J. A. História da educação brasileira. 4. ed. São Paulo: Ibras, 1986.

TORRES, R. M. Educação integral no enfrentamento de iniqüidades sociais, 2005 , São Paulo. (Mimeo).

WEREBE, M. J. G. 30 anos depois: grandezas e misérias do ensino no Brasil. São Paulo: Ática, 1994. 